\title{
Treatment of the on-off syndrome in Parkinsonism with low dose bromocriptine in combination with levodopa
}

\author{
D. N. B A T E M A N,A.COXON, N.J. L E G G, \\ A N D J . L. R E I D \\ From the Departments of Clinical Pharmacology and Neurology, Royal Postgraduate Medical School \\ and Hammersmith Hospital, London
}

S U M MARY The addition of bromocriptine, given in divided doses up to $30 \mathrm{mg}$ per day, to conventional anti-Parkinsonism therapy has been studied in a double-blind placebo controlled clinical trial in 11 patients with Parkinsonism with the "on-off" syndrome. Four patients withdrew because of side effects. Of the seven remaining, three had clinical benefit from bromocriptine with reduction in severity and frequency of fluctuations. There was, however, no statistically significant benefit of bromocriptine when the group as a whole was assessed in terms of severity or frequency of fluctuations measured by three different methods. The mean frequency of major fluctuations on placebo was $2.9 /$ day and on bromocriptine $1.8 /$ day $(\mathrm{P}<0.1>0.05)$. There appears to be a limited role for bromocriptine as additional therapy in the management of some patients with the on-off syndrome.

Long-term therapy with levodopa-containing preparations in patients with Parkinson's disease is now known to be accompanied by a number of clinical syndromes and a general deterioration in symptoms with time (Marsden and Parkes, 1977). Increasing deterioration in mental function with confusional states is one problem (Sweet et al., 1976). Another is that of sudden fluctuations in performance, the "on-off" syndrome (Damasio et al., 1973; Sweet and McDowell, 1974) which is increasingly frequent in patients who have been on therapy for five years or more. On-off effects may manifest different clinical features reflecting several underlying mechanisms (Marsden and Parkes, 1977).

Bromocriptine (CB 154) acts directly on dopamine receptors, and has a significant anti-Parkinsonism action (Calne et al., 1974; Teychenne et al., 1975). Two recently published clinical trials of bromocriptine have suggested that this agent may benefit patients with fluctuations in performance on levodopa (Kartzinel and Calne, 1976; Lieberman et al., 1976). In the former study optimal sympto-

Address for correspondence and reprint requests: Dr D. N. Bateman, Wolfson Unit of Clinical Pharmacology, Claremont Place, The University, Newcastle upon Tyne NE1.

Accepted 16 June 1978 matic relief was noted during a crossover period when bromocriptine was given together with levodopa. Bromocriptine in high doses has unwanted side effects and is expensive, and it is, therefore, of some importance to know whether the combination of levodopa and bromocriptine is effective in reducing the frequency and severity of on-off fluctuations.

This study was designed to assess the benefit of an addition of a small dose of bromocriptine to patients on regular anti-Parkinsonism medication.

\section{Patients and methods}

Patients with fluctuations of performance on levodopa-containing preparations were recruited for the study. No attempt was made to select patients who had one particular type of fluctuation, for example, end-of-dose akinesia, as opposed to rapid interdose fluctuations or hypotonic freezing. Before entry into the trial a concerted attempt was made to improve control of symptoms by adjusting the patients' therapeutic regimes in terms of dose size and frequency as well as drug content. Only if this was unsuccessful were patients then invited to enter the formal study. 
Table 1 Drug therapy of patients completing the study

\begin{tabular}{|c|c|c|c|c|}
\hline Patient & Sinemet & Anticholinergic & Imipramine & Bromocriptine \\
\hline 2 & $1106 \times /$ day & Benztropine $2 \mathrm{mg} 2 \times /$ day & $25 \mathrm{mg} 3 \times /$ day & $12.5 \mathrm{mg} /$ day \\
\hline 4 & $1103 \times /$ day & Benzhexol $2 \mathrm{mg} 2 \times /$ day & & $30 \mathrm{mg} /$ day \\
\hline 5 & $110 \frac{1}{2} 4 \times /$ day & Benzhexol $2 \mathrm{mg} 4 \times /$ day & & $10 \mathrm{mg} /$ day \\
\hline 6 & $110 \frac{1}{2} 4 \times /$ day & Orphenadrine $50 \mathrm{mg} 4 \times /$ day & & $20 \mathrm{mg} /$ day \\
\hline 7 & $275 \mathrm{~T} 4 \times /$ day & & & $30 \mathrm{mg} / \mathrm{day}$ \\
\hline 10 & 275 T $4 \times /$ day & & & $20 \mathrm{mg} /$ day \\
\hline 11 & 275 T $5 \times /$ day & & & $12.5 \mathrm{mg} /$ day \\
\hline
\end{tabular}

Eleven patients agreed to enter the trial. Ethical approval was obtained from Ethics Committee of the Royal Postgraduate Medical School, and a written consent was obtained from each patient. All the patients had idiopathic Parkinsonism except one who had postural hypotension and sexual dysfunction in addition to extrapyramidal features (Shy-Drager syndrome). Details of therapy are shown in Table 1 . All patients had received levodopa for at least two years (range two to seven years), and had derived symptomatic benefit. The age range of the patients was 36-72 years (mean $58.1 \mathrm{yr}$ ).

\section{DESIGN}

The trial was of double-blind, crossover, placebo controlled design. Patients were randomised independently by the hospital pharmacy, and received identical tablets of placebo or bromocriptine. Each of the two trial phases (active or placebo) was in two parts. During the first four weeks an incremental dosage of tablets (bromocriptine $2.5 \mathrm{mg}$ or placebo) was taken, increments being one tablet every second day. The maximum possible dose was $30 \mathrm{mg} /$ day-that is, four tablets three times per day. Dosage increase was limited by dyskinesia, hallucinations, nausea, or palpitations. A maximal tolerated dose of bromocriptine was thus established in each individual. Patients continued on this dose for a further six weeks during which they were seen every two weeks. At each of these three visits assessments were carried out as described below. Patients were then crossed over to a new four weeks build-up phase and a further six weeks assessment programme.

The assessments were as follows. (1) Blood pressure and pulse rate recorded after five minutes lying and two minutes standing: blood pressure was taken in duplicate with a Roche 1217 automatic sphygmomanometer, and pulse rate by a one minute radial pulse count. (2) A self-scored visual analogue scale of writing, walking, tremor, speech, and global severity of the fluctuations: this consisted of a $100 \mathrm{~mm}$ line marked as normal and maximal disability at opposite poles (Greenacre et al., 1976). Patients were asked to mark the degree of severity of their disability on it. (3) Assessment of a day's pattern of response in terms of fluctuation in performance by a self-scored visual analogue scale, this was marked by the patients at home every two hours for a normal day once every two weeks. (4) Self-administered questionnaire: a questionnaire relating severity and frequency of fluctuation was completed. (5) Assessment of symptoms and signs of Parkinsonism by an independent neurologist unaware of the trial design or protocol: the assessment consisted of grading symptoms and signs on an arbitrary 0-4 point scale as previously described (Calne et al., 1971). (6) Compliance with therapy: this was checked by tablet counts.

\section{ANALYSIS}

Statistical analysis of the neurological assessments was performed by a non-parametric Freidman twoway analysis of variance (Siegel, 1956). Visual analogue scales were subjected to arc-sine transformation to normalise the distribution (Armitage, 1971), and these and blood pressure recordings were analysed by Student's paired $t$ test.

\section{Results}

Eleven patients entered the study. Four had unacceptable side effects on bromocriptine and withdrew. Two patients had severe postural symptoms with orthostatic hypotension after the first dose of bromocriptine. The other two had headache and nasal stuffiness. Seven patients completed both phases of the trial. Dosage increase of bromocriptine was limited in five of the seven patients - in three because of dyskinesia, in one because of hallucinations and nausea, and in one because of palpitations and dyskinesia. The mean bromocriptine dose was $19.3 \mathrm{mg} /$ day (Table 1).

In all the patients there was some relationship between the time of dosing with levodopa and functional variability. This usually comprised increasing stiffness before the next L-dopa dose and dyskinesia associated with levodopa. These particular features tended to be more severe as the day progressed. Patients 2, 4, 5, and 6 also ex- 
Table 2 Self-scored visual analogue scales of Parkinsonism symptoms. Mean $( \pm S E M)$ of three observations on seven patients on each regimen. Disability is marked on a $100 \mathrm{~mm}$ line from maximal dysfunction and measured in $\mathrm{mm}$. None of these numbers reach statistically significant difference

\begin{tabular}{llrlc}
\hline & $\begin{array}{l}\text { Bromo- } \\
\text { criptine }\end{array}$ & $S E$ & Placebo & $S E$ \\
\hline Distance from unable to write & 80.3 & 8.9 & 76 & 10 \\
Distance from severe tremor & 72.8 & 7.9 & 76.1 & 6.7 \\
$\begin{array}{l}\text { Distance from unintelligible } \\
\text { speech }\end{array}$ & 73.6 & 11.6 & 76.7 & 7.9 \\
$\begin{array}{l}\text { Distance from unable to walk } \\
72\end{array}$ & 8.4 & 62 & 11.5 \\
\hline
\end{tabular}

perienced swings both of dyskinesia and akinesia unrelated to dosage.

In three of the patients $(2,6,7)$ there was a definite, clinically useful decrease in fluctuation with bromocriptine, and this is illustrated for patient 7 (Fig. 1). He was a lithograph etcher, and had found increasing difficulty with his profession before the introduction of bromocriptine because of swings in performance. After the addition of the drug these were completely abolished but they returned during the placebo phase. This was the most dramatic effect of bromocriptine observed in this study. In the group as a whole there was no significant improvement in the rating of the fluctuations as judged by the visual analogue scales

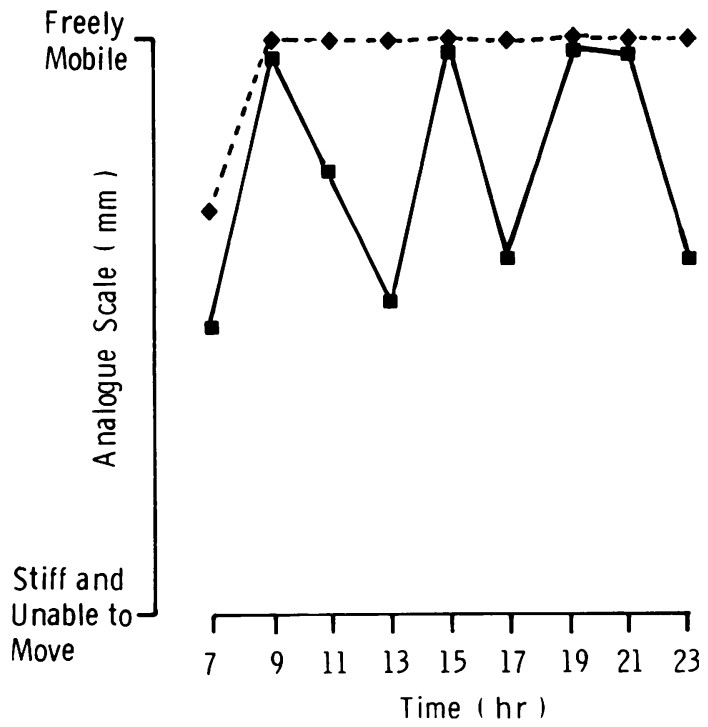

Fig. 1 Therapeutic response in patient 7 measured by a self-scored rating scale every two hours through the waking day. $\square=$ placebo, $>$ bromocriptine. Times of dosing with Sinemet 275 were 0700, 1200, 1700 , and $2300 \mathrm{hr}$. Placebo or bromocriptine was given at 0700, 1200, and $1700 \mathrm{hr}$.
(Fig. 2) or by the questionnaires. The scoring of major fluctuations throughout a day did reveal that the frequency of these fluctuations was less on bromocriptine therapy. The mean frequencies ( \pm SEM) were $2.9 \pm 0.75 /$ day on placebo and $1.8 \pm 0.64$ /day on bromocriptine (P0.1>0.05).

There was no significant change in overall symptoms or signs of Parkinsonism as measured by the visual analogue scale (Table 2 ) or the neurologist's assessments.

There was a significant fall in lying systolic blood pressure and standing diastolic blood pressure with bromocriptine therapy (Table 3). One patient (10) developed a severe exacerbation of tremor when the bromocriptine she had received in the first part of the trial was replaced by placebo. This was managed by increasing the dose of levodopa, and the tremor waned over the next three weeks.

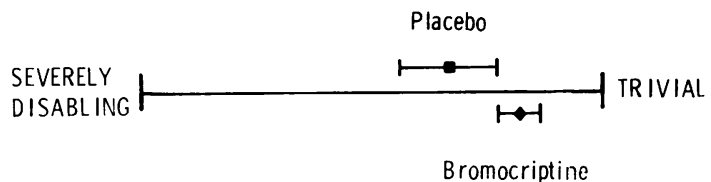

Fig. 2 Visual analogue scores of severity of fluctuations marked on three occasions on each treatment by seven patients (mean \pm SEM) $P>0.05$. $\mathbf{\square}=$ placebo, $\Delta=$ bromocriptine

Table 3 Blood pressure and pulse measurements on bromocriptine and placebo

\begin{tabular}{llrrrrl}
\hline & & \multicolumn{1}{c}{$\begin{array}{l}\text { Bromo- } \\
\text { criptine }\end{array}$} & & & \\
\cline { 3 - 6 } & & & $S E$ & & $S E$ & \\
\hline Lying & Systolic (mmHg)) & 126.9 & 4.90 & 134.6 & 5.53 & P $<0.01$ \\
& Diastolic (mmHg) & 82.2 & 2.81 & 84.8 & 2.28 & NS \\
& Pulse (beats/min) & 73.4 & 1.57 & 74.5 & 1.76 & NS \\
Standing & Systolic (mmHg) & 131.5 & 6.03 & 131.0 & 4.57 & NS \\
& Diastolic (mmHg) & 85.9 & 3.02 & 90.5 & 2.65 & P<0.05 \\
& Pulse (beats/min) & 82.2 & 1.84 & 85.7 & 1.92 & NS \\
& & & & & & \\
\hline
\end{tabular}

\section{Discussion}

The aetiology of the on-off syndrome in Parkinsonism patients on chronic therapy with L-dopa is not known. In particular it is not clear whether it is a manifestation of progression of the Parkinsonism disease process or a consequence of longterm levodopa administration. The relatively short plasma half-life of L-dopa with resultant fluctuating plasma concentration may contribute to the phenomenon (Damasio et al., 1973; Sweet and McDowell, 1974). Bromocriptine has a longer duration of action in animals (Johnson et al., 1976) and may have a longer half-life. Fluctuations may 
be caused by changes in dopamine formation and release in the central nervous system. As levodopa has to be converted in the basal ganglia to the active neurotransmitter dopamine, the use of direct dopamine agonist compounds has theoretical advantages over levodopa.

The on-off syndrome is not a homogeneous entity and comprises a number of different syndromes (Marsden and Parkes, 1977). The results of this study show that bromocriptine administered with levodopa-containing preparations was of clinical benefit in some patients who had the onoff symptoms. In addition, side effects were prominent, and four of the 11 patients withdrew because of them. There were, however, a small number of patients who did have a clear improvement in the frequency and severity of fluctuations in performance when taking a combination of L-dopa and low dose bromocriptine (Fig. 1). There was no change in symptoms or signs of Parkinsonism with addition of bromocriptine, and this was probably because treatment regimes had been carefully adjusted before the trial, and patients were thus on optimal antiParkinsonism therapy. Bromocriptine dosage was not increased beyond that at which side effects initially occurred as this could only have been achieved by reducing the levodopa dose and we felt this would complicate the study unduly.

In this study there were no clear factors predicting which patients would respond to bromocriptine. In particular, response did not appear to be determined by age, duration of disease, or duration of levodopa therapy. However, the three patients who did respond all had end-of-dose deterioration as a prominent feature. Bromocriptine thus appears to have a clinically useful role in some patients with the on-off syndrome. The proportion of patients with fluctuations who improved in this small study is similar to that reported to respond to Deprenyl, a monoamine oxidase type B inhibitor (Lees et al., 1977).

Severe tremor occurred in one patient on withdrawal of bromocriptine. We have previously observed marked deteriorations in clinical state after stopping bromocriptine to a degree of functional impairment worse than that before the drug was given. The deterioration slowly resolved on levodopa therapy over two to three months. It is possible that tachyphylaxis to dopamine occurs in patients taking dopamine agonists. This could involve a reduction in receptor sensitivity which would be the converse of the reputed supersensitivity of dopamine receptors after long-term treatment with dopamine receptor antagonists (Moore and Thornburg, 1975).
It seems that there may be a role for the combination of low doses of bromocriptine with levodopa preparations in the treatment of some patients with on-off effects. Such additional therapy should be introduced with care in view of the possible side effects, and should also be of short duration if there is no clear improvement, in view of possible changes in receptor sensitivity in the basal ganglia after bromocriptine.

We wish to thank Sandoz for supplies of bromocriptine and matching placebo tablets. Nurse Julia Daniel assisted with the measurements of blood pressure. Hammersmith Hospital Pharmacy kindly organised the supply of tablets to patients and the randomisation code. Miss Aviva Petrie gave expert statistical advice, and Miss Bernadette Edinborough typed the manuscript.

\section{References}

Armitage, P. (1971). Statistical Methods in Medical Research. Blackwell: London.

Calne, D. B., Reid, J. L., Vakil, S. D., Rao, S., $\stackrel{\oplus}{\sim}$ Petrie, A., Pallis, C. A., Gawler, J., Thomas, P. K., ワ and Hilson, A. (1971). Idiopathic Parkinsonism $\circ$ treated with an extra-cerebral decarboxylase inhibitor in combination with laevodopa. British Medical Journal, 3, 729-732.

Calne, D. B., Teychenne, P. F., Leigh, P. N., Bamji, A. N., and Greenacre, J. K. (1974). Treatment of Parkinsonism with bromocriptine. Lancet, 2, 13551356.

Damasio, A. R., Castro-Caldos, A., and Levy, A. (1973). The "on-off" effect. In Advances in Neurology, 3, 11-22. Edited by D. B. Calne. Raven Press: New York.

Greenacre, J. K., Coxon, A., Petrie, A., and Reid, J. L. (1976). Comparison of levodopa with carbidopa or benserazide in Parkinsonism. Lancet, 2, 381-384.

Johnson, A. M., Loew, D. M., and Vigouret, J. M. (1976). Central dopamine stimulant properties of bromocriptine in comparison to apomorphine, Damphetamine and L-dopa. British Journal of Pharmacology, 56, 59-68.

Kartzinel, R., and Calne, D. B. (1976). Studies with bromocriptine. Part 1. "On-off" phenomena. Neurology (Minneapolis), 26, 508-510.

Lees, A. J., Shaw, K. M., Kohout, L. J., Stern, G. M., Elseworth, J. D., Sandler, M., and Youdim, M. B. H. (1977). Deprenyl in Parkinson's disease. Lancet, 2, 791-795.

Lieberman, A., Kupersmith, M., Estey, E., and Goldstein, M. (1976). Treatment of Parkinson's disease with bromocriptine. New England Journal of Medicine, 295, 1400-1404.

Marsden, C. D., and Parkes, J. D. (1977). Success and problems of long-term levodopa therapy in Parkinson's disease. Lancet, 1, 345-349. 
Moore, K. E., and Thornburg, J. E. (1975). Drug induced dopaminergic supersensitivity. In Advances in Neurology. Vol. 9, pp. 93-104. Edited by D. B. Calne, T. N. Chase and A. Barbeau. Raven Press: New York.

Siegel, S. (1956). Non-parametric Statistics for the Behavioral Sciences. McGraw-Hill: New York.

Sweet, R., and McDowell, F. (1974). The "on-off" response to chronic L-dopa treatment of Parkinsonism. In Advances in Neurology. Vol 5, pp. 331338. Edited by F. H. McDowell and A. Barbeau.
Raven Press: New York.

Sweet, R. D., McDowell, F. H., Feigenson, J. S., Loranger, A. W., and Goodell, H. (1976). Mental symptoms in Parkinson's disease during chronic treatment with levodopa. Neurology (Minneapolis), 26, 305-310.

Teychenne, P. F., Calne, D. B., Leigh, P. N., Petrie, A., Reid, J. L., Greenacre, J. K., and Bamji, A. N. (1975). Idiopathic Parkinsonism treated with bromocriptine. Lancet, 2, 473-476. 